Research Article

\title{
Characteristics of Jerk Response Spectra for Elastic and Inelastic Systems
}

\author{
Haoxiang He, ${ }^{1,2}$ Ruifeng Li, ${ }^{1}$ and Kui Chen ${ }^{1}$ \\ ${ }^{1}$ Beijing Key Laboratory of Earthquake Engineering and Structure Retrofit, Beijing University of Technology, \\ Beijing 100124, China \\ ${ }^{2}$ Beijing Collaborative Innovation Center for Metropolitan Transportation, Beijing 100124, China \\ Correspondence should be addressed to Haoxiang He; hhx7856@163.com
}

Received 7 March 2014; Revised 28 September 2014; Accepted 4 October 2014

Academic Editor: Longjun Dong

Copyright (C) 2015 Haoxiang He et al. This is an open access article distributed under the Creative Commons Attribution License, which permits unrestricted use, distribution, and reproduction in any medium, provided the original work is properly cited.

\begin{abstract}
Jerk is the time rate of acceleration and mainly represents the nonstationary component in high frequency band of the earthquake wave. The study on jerk and its response spectra can enhance the recognition of the nonstationary ground motion. The mechanical meaning and research value of jerk are described. Jerk is recommended to be solved by establishing state-space equations and Runge-Kutta method. The solution method of elastic and inelastic jerk response spectra under ground motion is established, and the accurate jerk spectrum should be calculated directly according to numerical computing instead of pseudo-acceleration spectrum. The characteristics of jerk response spectra are studied according to the influencing factors, such as site condition, amplification factor, ductility factor, and reduction factor. The concept of impact reduction factor is presented. The statistical results show that the jerk spectrum has similar rules as the acceleration spectrum, and the amplitude is relative to the predominant period, especially for structures with short or medium period. If the ductility is improved, the effective jerk will reduce obviously, and the impact reduction factor will be enhanced. Different from the strength reduction factor, the impact reduction factor is nearly not relevant to the period.
\end{abstract}

\section{Introduction}

The ground motion is a process of random variation about time and space. The seismic wave and propagation observed in earthquake records demonstrate evidently nonstationary characteristics for both time domain and frequency domain. That is, the intensity of the ground motion (acceleration, velocity, or displacement) varies with time, and the frequency has wide content and dispersive effect $[1,2]$. Thus, nonstationary characteristics of the intensity and frequency of the ground motion are deeply concerned with and viewed as the important factors having a significant impact on the seismic response of structures. It is important to evaluate the dynamic properties and spectral characteristics of actual buildings using strong motion records because the structures often reveal distinctive characters under seismic excitations and the structures are both nonlinear and time variant under such conditions.
At present, the primary measurement and analysis parameters for ground motion are displacement, velocity, and acceleration, which are well studied for various seismic source mechanisms, ground motion characteristics, and engineering applications in earthquake engineering. In addition, more global or novel parameters such as $\mathrm{P}$-wave energy, S-wave energy [3], tectonic stress [4], seismic moment [5], and seismic source location [6] are always very important for ground motions, and the detailed variations and nonstationarity in time domain or frequency domain can be detected. In general, the research on the time-frequency characteristic of ground motions and the dynamic effect on the engineering structure needs more intensive study, especially on the parameter property in the field of seismophysics and earthquake engineering.

Even though study on the primary parameters can also be enhanced in order to develop the spectra characteristic of ground motions, jerk which means the derivative 
of acceleration with respect to time is a parameter not intensively studied as yet. In fact, the jerk record contains a wealth of implicit information about ground motion; as other critical parameters and responses, the research on jerk and its spectrum can enhance the understanding of the seismic nonstationarity more intensively and completely. Furthermore, the limitations of some traditional solving methods in structural dynamics can be found and the seismic design philosophy also can be improved.

In this paper, the mechanic meaning and research value of jerk are described firstly, and then the dynamic solution method for jerk is discussed. The characteristics and the factors of the elastic and inelastic response spectra are studied.

\section{Mechanical Significance of Jerk}

Jerk can be defined as the changing rate of acceleration with respect to time [7], and its international unit is $\mathrm{m} / \mathrm{s}^{3}$. According to Newton's second law of motion, jerk is viewed as the change of force magnitude for a unit mass in unit time. Studies have shown that jerk is closely related to the physical mutation and destruction process. In recent years, jerk and relative parameters are applied in the tracking and positioning for Global Positioning System (GPS), the high-speed dynamic vehicle tracking, the automatic control of high-speed machines, and comfort evaluation for highspeed trains and elevators [8-10]. The physical and dynamic meaning of the series dynamic parameters is summarized in Table 1. It is obvious that the jerk and the integral of the displacement with respect to time also have determined an important significance.

In earthquake engineering, the basic characteristics of jerk are evaluated based on records from the 1999 Chi-Chi earthquake, earthquake and one of its aftershocks. It is found that the maximum of jerk at a free-field station was over $312 \mathrm{~m} / \mathrm{s}^{3}$, and the effective duration, between the first and the last time $20 \mathrm{~m} / \mathrm{s}^{3}$, was almost one minute near the epicenter area [11]. A type of jerk sensor was developed for earthquake wave measurement and its performance was proved in experiment and Wenchuan earthquake [12]. In structural control, a quadratic regulator is derived for the total structural jerk that produces a single algebraic Riccati equation to define the control gains. The control method developed is shown to be more effective than typical displacement-focused active and semiactive civil structural control methods [13]. Although jerk has potential significance for earthquake engineering, the time-frequency characteristics of jerk are not definite until now, not to mention the study on the jerk spectrum.

The jerk in strong nonstationary ground motion values is often great. For example, in the Chi-Chi earthquake in Taiwan, the peak of the maximum jerk obtained by the seismic stations is more than $312 \mathrm{~m} / \mathrm{s}^{3}$, complex, and everchanging schedule, and the spectral properties have aroused the attention of researchers. Typical acceleration and jerk comparison of Taiwan Chi-Chi earthquake are shown in Figure 1, including near-field and far-field records, indicating the instantaneous changes of jerk and highlighting the pulse effect or the impact effect. As another example, the acceleration waves and jerk waves in Wenchuan earthquake in 2008 are shown in Figure 2. It is clear that the amplitude of jerk changes dramatically, and the site effect and the distance from epicenter affect the frequency spectrum of jerk evidently. Hence, more research should focus on the characteristics of jerk.

\section{Solution Method for Dynamic Equations Related to Jerk}

For a damped structure system subjected to earthquake loads, the corresponding equation of motion is generally written as follows:

$$
\mathbf{M} \ddot{\mathbf{X}}+\mathbf{C} \dot{\mathbf{X}}+\mathbf{K X}=-\mathbf{M} \ddot{\mathbf{X}}_{g}(t)
$$

where $\mathbf{M}, \mathbf{C}$, and $\mathbf{K}$ are the system mass, damping, and stiffness matrix, respectively. $\mathbf{X}$ is the displacement response for the structure and $\ddot{\mathbf{X}}_{g}(t)$ is acceleration vector.

The above equation can be solved by numerical method; thus, the structural dynamic response including acceleration and displacement can be obtained. The jerk value can be calculated by solving the time derivative of acceleration. For solving jerk, it is worth noting that some traditional stepby-step integration methods such as the Newmark method and Wilson- $\theta$ method that are commonly used in earthquake engineering involve the dubious basic assumptions and inaccuracy. In general, the above integration methods assume that the acceleration is constant or linear variation during the interval of time $[14,15]$, which will lead to the jerk in the interval, is assumed to be 0 or a constant, and this assumption is not in accordance with the real condition.

In addition, the Newmark method is unconditionally stable and the maximum accuracy is at the second order, and the Wilson- $\theta$ method also has second order accuracy. Hence, these two methods do not fully meet the precision for solving jerk. In this case, Runge-Kutta method which is constructed based on Taylor series, especially the fourth-order RungeKutta method, has obvious advantages. For the fourth-order Runge-Kutta method, the smoothness of time-varying signal is completely considered, and this method with fourthorder accuracy is stable. In view of the Runge-Kutta method it is required that a second-order differential equation be transformed into a first-order differential equation; by using the state space method and introducing state variable, (1) may be written as first order differential equations.

Define system state vector as follows: $\mathbf{U}=\{\mathbf{X}, \dot{\mathbf{X}}\}^{\mathrm{T}}$ and $\mathbf{V}=\{\mathbf{X} \ddot{\mathbf{X}}\}^{\mathrm{T}}$; then (1) is expressed as the following state-space equations:

$$
\dot{\mathbf{U}}=\mathbf{A} \mathbf{U}+\mathbf{B} \ddot{\mathbf{X}}_{g}(t) \quad \mathbf{V}=\mathbf{D} \mathbf{U}+\mathbf{E} \ddot{\mathbf{X}}_{g}(t),
$$


TABLE 1: Significance of dynamic parameters and research level.

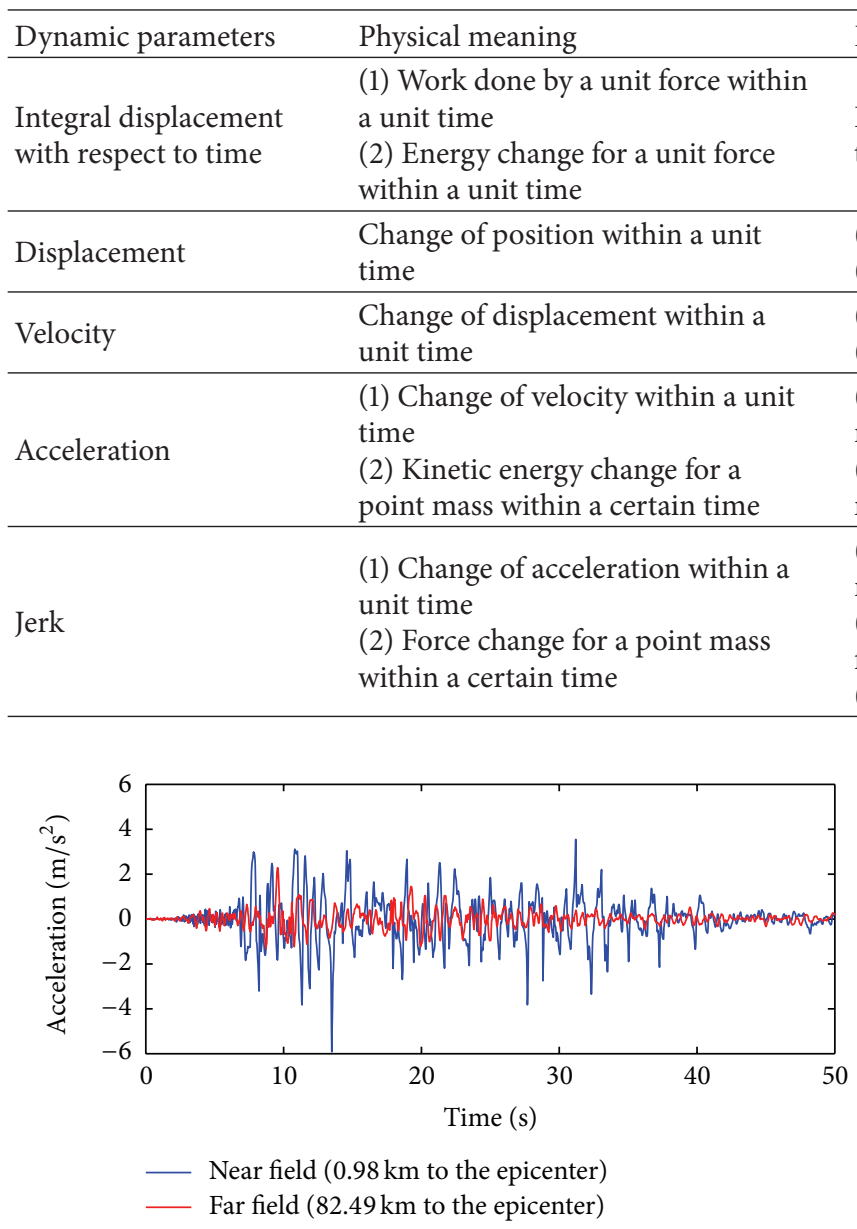

(a)

Dynamical meaning Research extent

Rate of change of energy with respect to time for a point mass

Needs further study

(1) Displacement for a point mass

(2) Deformation for a point mass

(1) Velocity or speed for a point mass

(2) Deformation rate for a point mass

(1) Rate of change of velocity with respect to time for a point mass

(2) Instantaneous force for a point mass

(1) Rate of change of acceleration with respect to time for a point mass
(2) Rate of change of instantaneous

force for a point mass

(3) Impact effect for a point mass
Comprehensively studied and widely used

Comprehensively studied and widely used

Comprehensively studied and widely used

\section{Almost empty \\ Almost empty}

FIGURE 1: Comparison of acceleration waves and jerk waves in Chi-Chi earthquake.

where

$$
\begin{aligned}
& \mathbf{A}=\left[\begin{array}{cc}
\mathbf{0} & \mathbf{I} \\
-\mathbf{M}^{-1} \mathbf{K} & -\mathbf{M}^{-1} \mathbf{C}
\end{array}\right], \\
& \mathbf{D}=\left[\begin{array}{cc}
\mathbf{I} & \mathbf{0} \\
-\mathbf{M}^{-1} \mathbf{K} & -\mathbf{M}^{-1} \mathbf{C}
\end{array}\right], \\
& \mathbf{B}=\mathbf{E}=\left[\begin{array}{c}
\mathbf{0} \\
-\mathbf{I}
\end{array}\right] .
\end{aligned}
$$

The structural acceleration response is solved from the above equations, and the jerk response is obtained by calculating the time derivation of the acceleration. With the improvement of acceleration measurement and the development of jerk acquisition instrument, a new state equation can be established according to jerk response assuming the structure is elastic and the jerk is calculated directly. On both sides of (1) the derivative with respect to time is given as

$$
\mathbf{M} \dddot{\mathbf{X}}+\mathbf{C X}+\mathbf{K} \dot{\mathbf{X}}=-\mathbf{M} \dddot{\mathbf{X}}_{g}(t)
$$

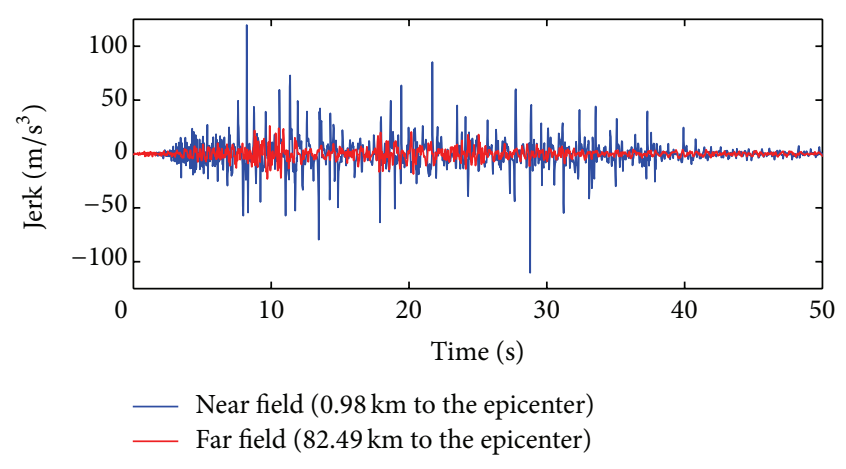

(b) 


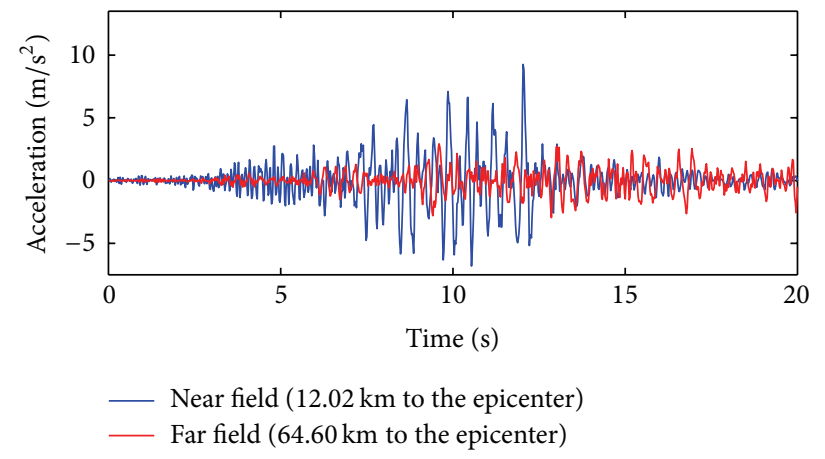

(a)

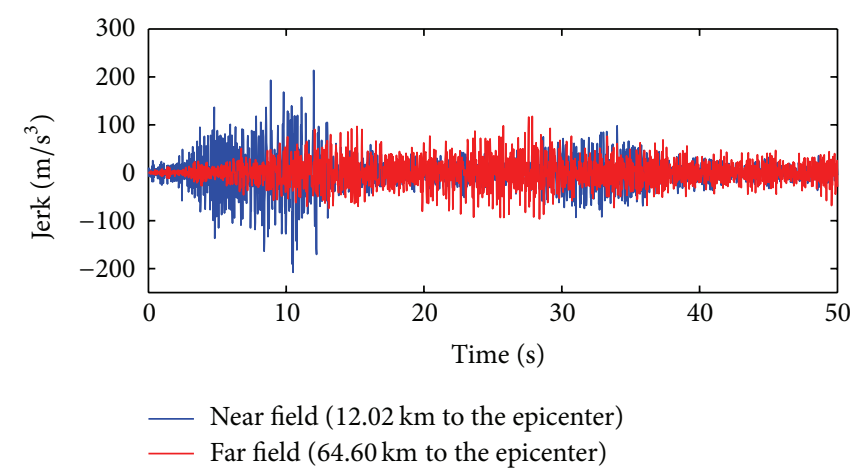

(b)

FIGURE 2: Comparison of acceleration waves and jerk waves in Wenchuan earthquake.

\section{Elastic Jerk Response Spectrum and the Corresponding Characteristics}

A response spectrum is simply a plot of the peak or steadystate response (displacement, velocity, or acceleration) of a series of oscillators of varying natural frequency that are forced into motion by the ground motion. The characteristics and mechanisms of spectra for displacement, velocity, and acceleration have been studied in all directions since the concept was presented by Biot and Housner in 1940s. However, the jerk spectrum is a new statement, the relative study is almost empty, and its characteristics need more attention.

Jerk response spectrum indicates the impulse effect of different oscillators of varying natural frequency that are subjected to earthquake. Study on the jerk response spectrum will contribute to comprehending the nonstationarity and impact effect of earthquake and improving the seismic design method for normal structures.

For a SDOF elastic system which is located on a rigid foundation, the mass, the damping coefficient, and the stiffness are expressed as $m, c$, and $k$, respectively. The equation of motion when the system is subjected to a ground motion is

$$
m \ddot{x}(t)+c \dot{x}(t)+k x(t)=-m \ddot{x}_{g}(t),
$$

where $x_{g}(t)$ is the displacement component and $x(t)$ is the displacement vector relative to the ground. Noting that $\zeta=$ $c /(2 m \omega), \omega^{2}=k / m$, substituting these into (7) gives

$$
\ddot{x}(t)+2 \zeta \omega \dot{x}(t)+\omega^{2} x(t)=-\ddot{x}_{g}(t) .
$$

Assume the initial displacement and initial velocity are both 0 ; the solution of (8) can be calculated according to Duhamel integral

$$
x(t)=-\frac{1}{\omega_{d}} \int_{0}^{t} \ddot{x}_{g}(\tau) e^{-\zeta \omega(t-\tau)} \sin \omega_{d}(t-\tau) d \tau,
$$

where $\omega_{d}=\omega \sqrt{1-\zeta^{2}}$ represents the damped frequency. The relative velocity, absolute acceleration, and absolute jerk are expressed, respectively, as

$$
\begin{aligned}
& \dot{x}(t)=\int_{0}^{t} \ddot{x}_{g}(\tau) e^{-\zeta \omega(t-\tau)}[ \frac{\zeta}{\sqrt{1-\zeta^{2}}} \sin \omega_{d}(t-\tau) \\
&\left.-\cos \omega_{d}(t-\tau)\right] d \tau \\
& a(t)=\ddot{x}(t)+\ddot{x}_{g}(t) \\
&=\omega_{d} \int_{0}^{t} \ddot{x}_{g}(\tau) e^{-\zeta \omega(t-\tau)}\left[\left(1-\frac{\zeta^{2}}{1-\zeta^{2}}\right) \sin \omega_{d}(t-\tau)\right. \\
&\left.\quad+\frac{2 \zeta}{\sqrt{1-\zeta^{2}}} \cos \omega_{d}(t-\tau)\right] d \tau
\end{aligned}
$$

$$
\begin{aligned}
j(t)=\dddot{x}(t)+\dddot{x}_{g}(t) & \\
=\omega_{d}^{2} \int_{0}^{t} \ddot{x}_{g}(\tau) e^{-\zeta \omega(t-\tau)} & {\left[\frac{4 \zeta^{3}-3 \zeta}{\left(1-\zeta^{2}\right)^{3 / 2}} \sin \omega_{d}(t-\tau)\right.} \\
& \left.+\frac{1-4 \zeta^{2}}{1-\zeta^{2}} \cos \omega_{d}(t-\tau)\right] d \tau .
\end{aligned}
$$

According to the above equations, the maximum system response for varying natural frequency can be continuously obtained by numerical integration method; thus, the displacement spectra $S_{d}$, the relative velocity response spectrum $S_{v}$, the absolute acceleration response spectra $S_{a}$, and the absolute jerk response spectrum $S_{j}$ are obtained. It is worth noting that the higher order terms of damping coefficient and cosine function in (9) to (11) are often ignored when the earthquake duration is long enough $[6,16]$. Hence, the relationships among spectral displacement, pseudospectral velocity, and pseudospectral acceleration are given by

$$
S_{a} \approx S_{p a} \approx \omega S_{p v} \approx \omega^{2} S_{d}
$$


TABLE 2: The ground motions used in this study.

\begin{tabular}{lccc}
\hline Time & Earthquake name & Magnitude (MS) & Records \\
\hline 1952 & Northern & 4.0 & 14 \\
1966 & Haicheng & 7.5 & 11 \\
1971 & Tangshan & 7.6 & 7 \\
1975 & Coyote & 5.8 & 15 \\
1975 & Imperial & 6.5 & 9 \\
1976 & Livermore & 5.8 & 14 \\
1979 & Morgan & 6.2 & 15 \\
1979 & Mexico & 8.1 & 5 \\
1980 & Palm & 5.9 & 15 \\
1984 & Whittier & 6.0 & 14 \\
1985 & Lancang-Gengma & 4.6 & 4 \\
1986 & Loma & 6.9 & 8 \\
1987 & Petrolia & 7.1 & 14 \\
1988 & Landers & 7.3 & 15 \\
1989 & Northridge & 6.7 & 15 \\
1992 & Kobe & 6.9 & 12 \\
1992 & Lijiang & 4.7 & 12 \\
1994 & Chi-Chi & 7.6 & 15 \\
1995 & Shidian & 5.9 & 4 \\
1996 & Northern & 4.0 & 14 \\
1999 & Haicheng & 7.5 & 13 \\
2008 & Wenchuan & 8.0 &
\end{tabular}

Through the assumption that the higher order terms of damping coefficient and cosine term are often ignored, the difference between relative velocity response spectrum and pseudo velocity spectrum is obvious in the lower frequency band for the structural responses in many earthquake records. The accumulated error will enlarge if the absolute jerk spectrum is calculated simply according to the recurrence formula $S_{j}=\omega S_{a}$. As an example, the real spectrum and pseudospectrum with varied response in $\mathrm{El}$ Centro NS record are shown in Figure 3, and this verifies the aforementioned conclusion. Thus, it is suggested that the absolute jerk spectrum is obtained by the statistical results of the numerical integration method and the specific formulas are shown as (2), (5), or (12).

To obtain the absolute jerk spectrum on different types of sites, a total of 250 horizontal acceleration records (see Table 2) from significant earthquakes in the world were used for the analysis. The records are classified based on the soil type and shear wave velocity according to NEHRP2009. By using the Runge-Kutta method and statistical analysis, a variety of elastic acceleration response spectra and elastic jerk response spectrum are calculated.

The normal response spectra (the spectrum about the absolute ratio of the maximum response value to the maximum amplitude of ground motion) with 5\% damping ration on different sites are shown in Figures 4 and 5. In each figure, the subgraphs represent the spectra of A to E soil type and the mean spectra of each soil type, respectively.
It can be seen from Figures 4 and 5 that the jerk response spectra and acceleration response spectra present similar shape in elastic state. However, the jerk spectra decay rapidly when the system period is larger than $1 \mathrm{~s}$ because the jerk response contains more information about the impact effect and high-frequency components in earthquake.

The amplification effect on jerk is obvious when the natural period is close to the predominant period of the site, and the maximum normal value is more than 6 . Compared to the rock site, the predominant period range in the soft soil site is larger, and the jerk response is more obvious for long period structure on soft site. In conclusion, the effect of jerk is advised to be considered especially when the structural fundamental period is less than the predominant period of the site during the seismic resistance design.

\section{Inelastic Jerk Response Spectrum and the Corresponding Characteristics}

The structure subjected to strong ground motion will inevitably be nonlinear, and the traditional inelastic response spectra of displacement and acceleration are widely studied in recent years. As the mechanism described above, the structural jerk inelastic response spectra will embody the damage induced by impact and pulse for the ductile structures. The equation of motion when the SDOF inelastic system is subjected to a ground motion is expressed as follows:

$$
m \ddot{x}(t)+c \dot{x}(t)+f(x, t)=-m \ddot{x}_{g}(t),
$$

where $f(x, t)$ is the restoring force of the system and other parameters are described as (7).

Assume that the yield displacement is $x_{y}$ and the nondimensional time history is $u(t)=x(t) / x_{y}$; then the equation above will be transformed as a nondimensional form

$$
\ddot{u}(t)+2 \zeta \omega \dot{u}(t)+\omega^{2} \frac{f(x, t)}{f_{y}}=-\frac{\omega^{2}}{\eta} \frac{\ddot{x}_{g}(t)}{\max \left(\left|\ddot{x}_{g}(t)\right|\right)},
$$

where the system damping ratio is expressed as $\zeta=c /(2 m \omega)$, the system circular frequency is $\omega=\sqrt{k / m}, f_{y}$ is the yield strength, and the standard intensity is defined as $\eta=$ $f_{y} /\left[m \cdot \max \left(\left|\ddot{x}_{q}(t)\right|\right)\right]$. The displacement ductility factor is $\mu=\max (|x(t)|) / x_{y}=\max (|u(t)|)$.

It can be seen from the above equation that the dynamic responses such as maximum acceleration, maximum jerk, and the ductility factor of a specified earthquake record can be determined, assuming that elastic period, damping ratio, and the restoring force form of the SDOF system are known. Thus, the inelastic response spectra with different displacement ductility can be established after the statistical induction for large number of earthquake records. The restoring force model is selected as the elastic perfectly plastic model in this paper, and the inelastic response spectra for different sites are obtained based on the records used for establishing the elastic response spectra.

Assuming that the damping ratio is $5 \%$, the acceleration inelastic response spectra for site $\mathrm{A}$ and site $\mathrm{C}$ are shown in Figures 6 and 7. The jerk inelastic response spectra for site A and site $\mathrm{C}$ are shown in Figures 8 and 9. 


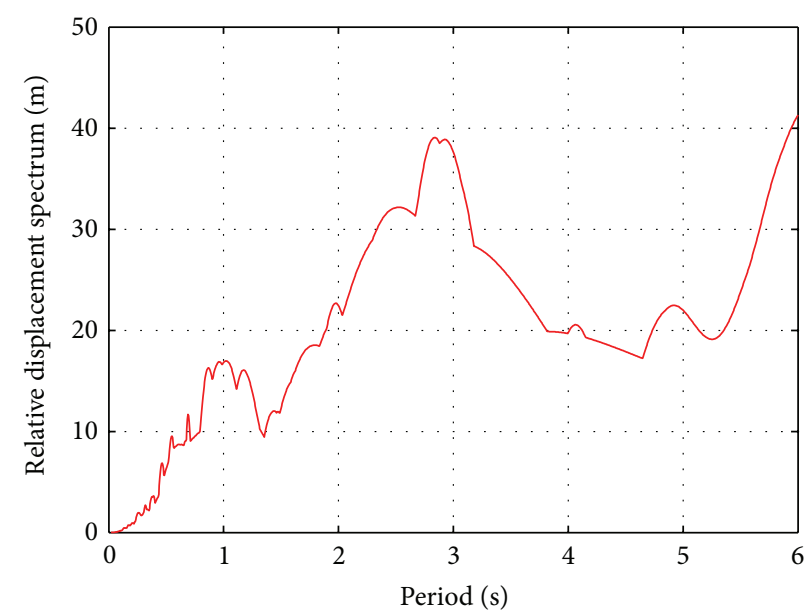

- Relative displacement spectrum

(a)

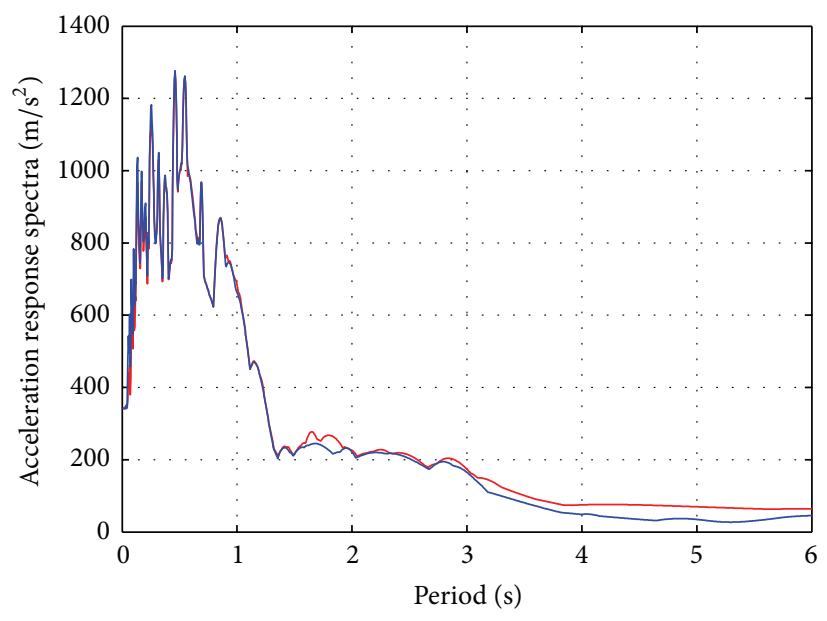

- Absolute acceleration spectrum

_ Pseudo acceleration spectrum

(c)

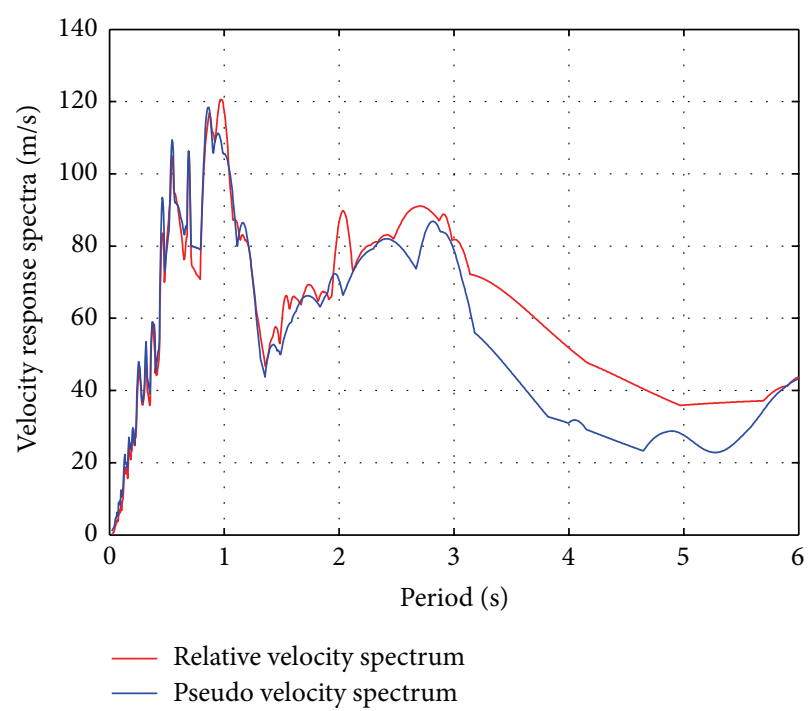

(b)

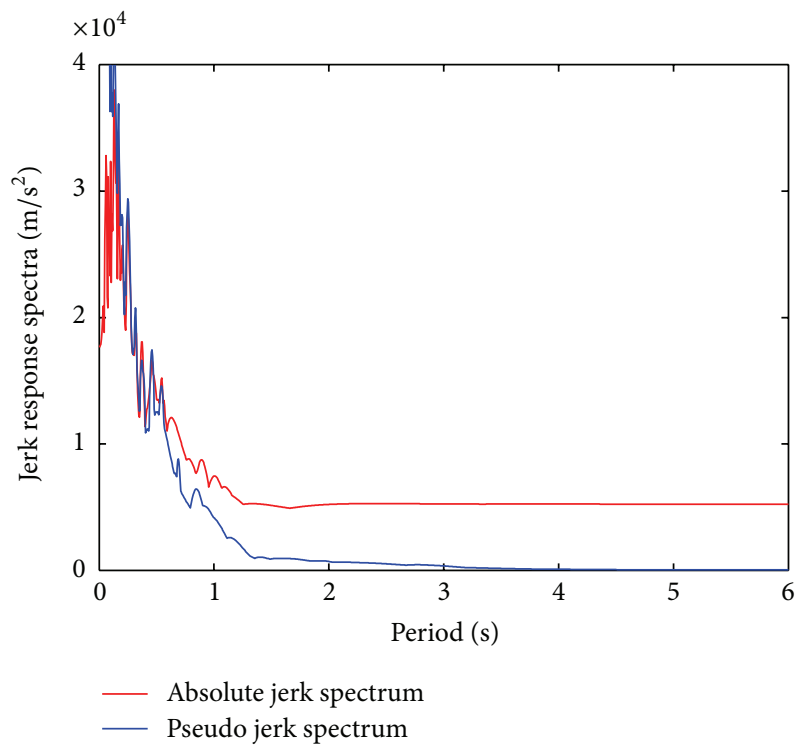

(d)

FIgURE 3: Comparison of real spectrum and pseudospectrum.

It can be concluded that the inelastic jerk response spectrum evidently attenuates compared to the corresponding elastic spectrum, and the attenuation effect is more noticeable while the attenuation degree decreases gradually for higher ductility spectrum. The jerk amplitude will reduce especially for long-period structures with various ductilities. Hence, it is effective to enhance the ductility or damping in the structural design to reduce the resistance force and the impact induced by earthquake. For soft ground conditions, the predominated period stage in jerk spectra is longer and the amplitude is larger compared to the response from rock site, so it is necessary to pay more attention to the jerk amplitude of the structure on soft site. Despite the site type, it is advised to consider the influence of the jerk as long as the structural period is less than 0.4 seconds even though the structure has high ductility. Hence, the dynamic design for the small and medium-sized structures should be paid more attention in order to assure adequate performance.

The actual design strength of structure will be lower than the structural strength assuming that the structure is elastic during the earthquake, considering the elastic and plastic deformation capacity of structure. Based on the existing research results, the strength reduction factor is defined as the ration of the maximum inertia force $f_{x e}$ of SDOF elastic system subjected to a given ground motion to the yielding strength $f_{y}$ required to maintain the displacement ductility ratio demand:

$$
R=\frac{f_{x e}}{f_{y}}
$$




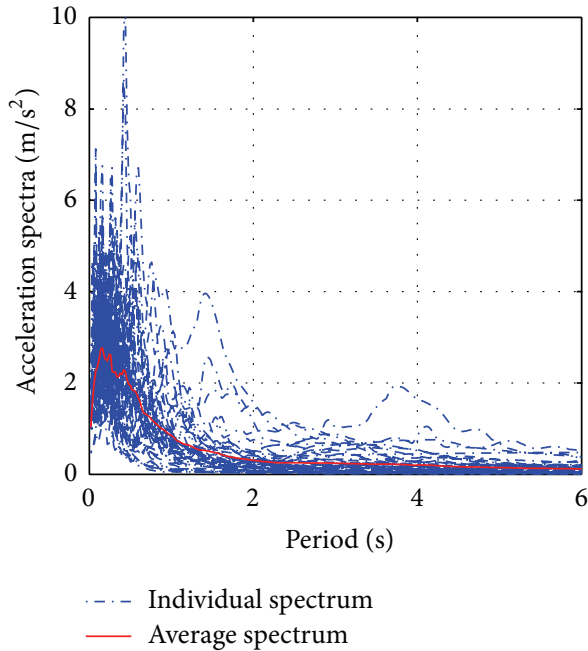

(a)

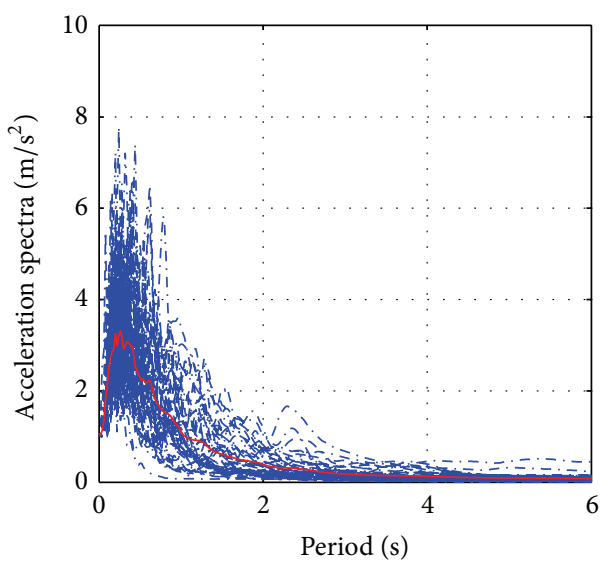

-. - Individual spectrum - Average spectrum

(c)

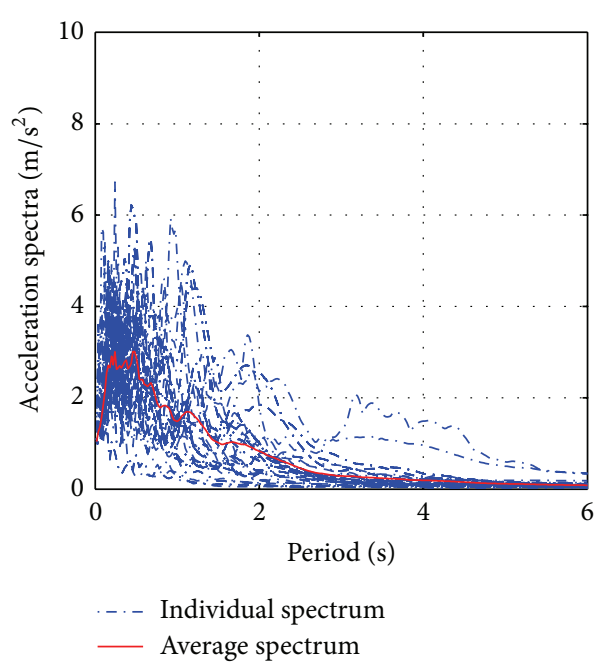

(e)

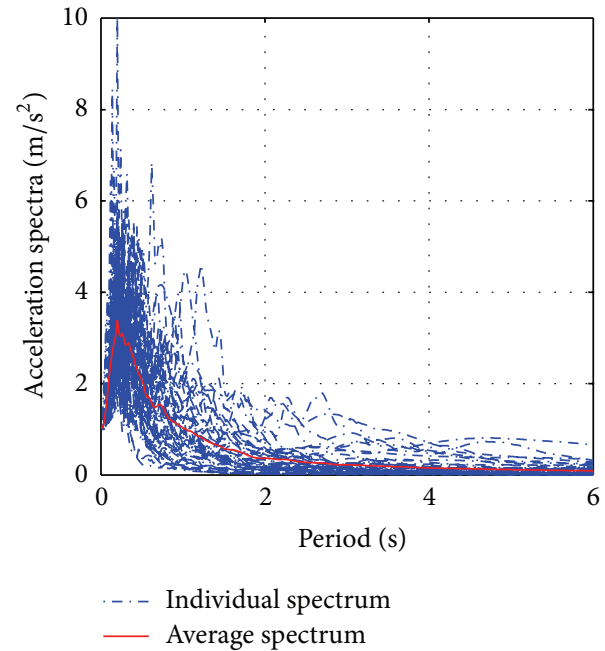

(b)

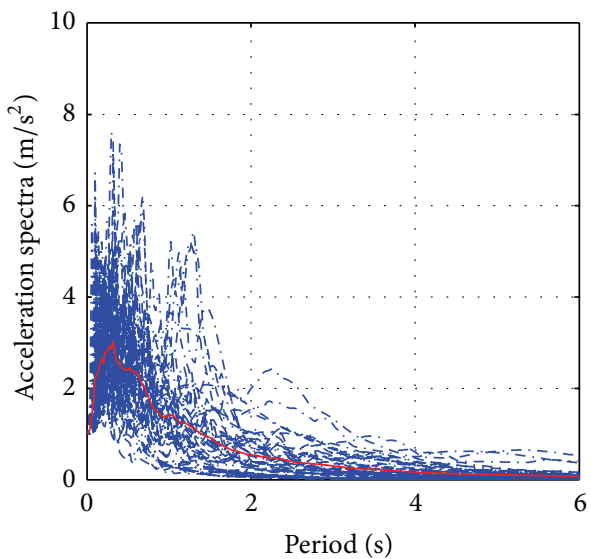

- - Individual spectrum _ Average spectrum

(d)

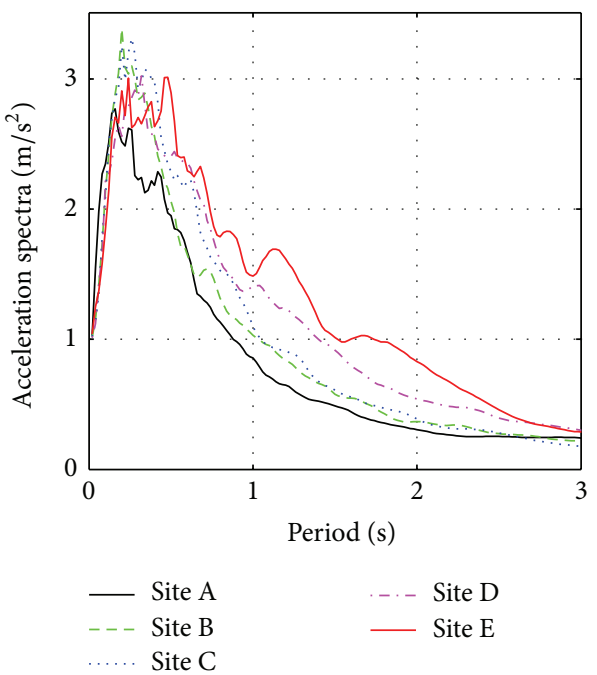

(f)

FIGURE 4: Normal acceleration response spectra for different sites. 

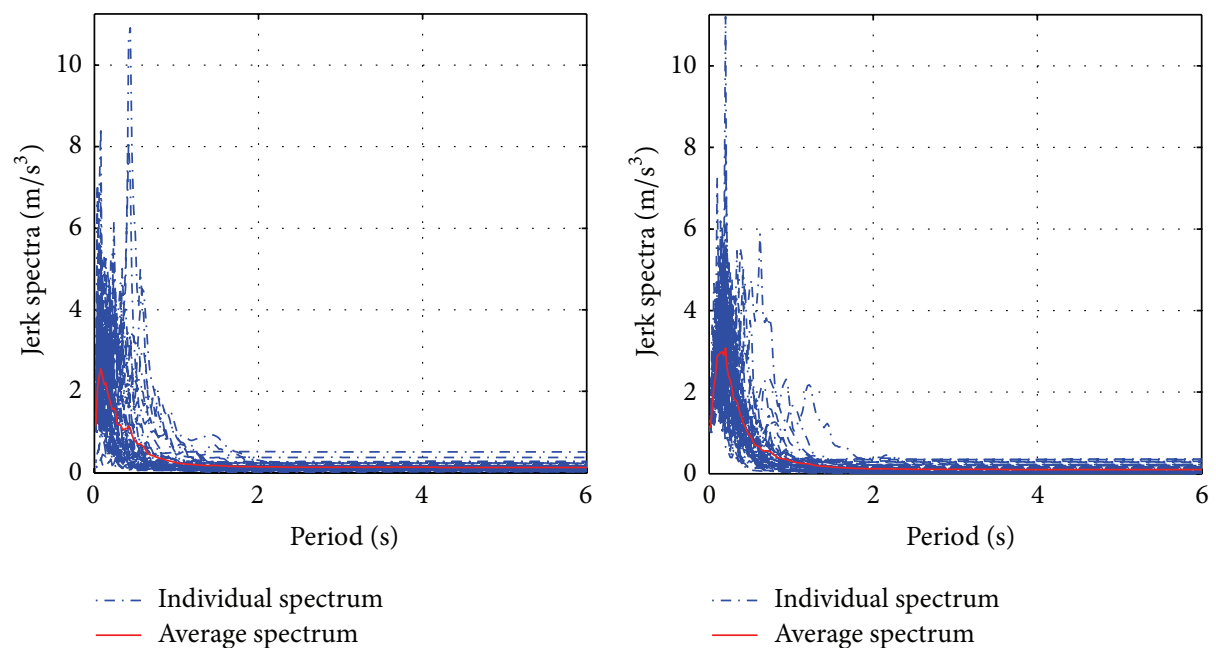

(a)
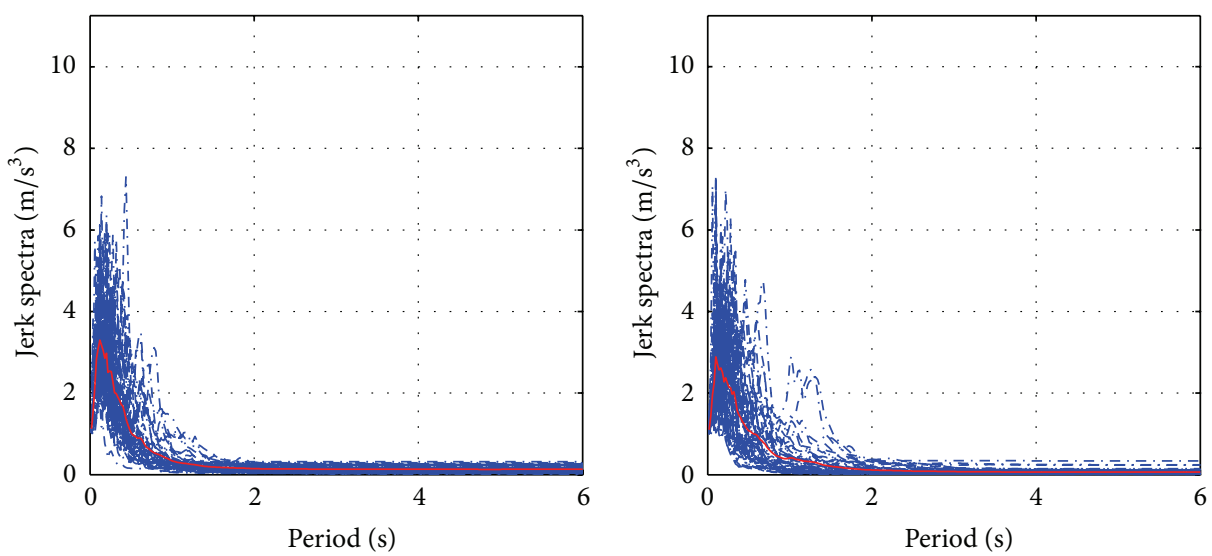

-. - Individual spectrum

_ Average spectrum

-. - Individual spectrum

__ Average spectrum

(c)

(d)
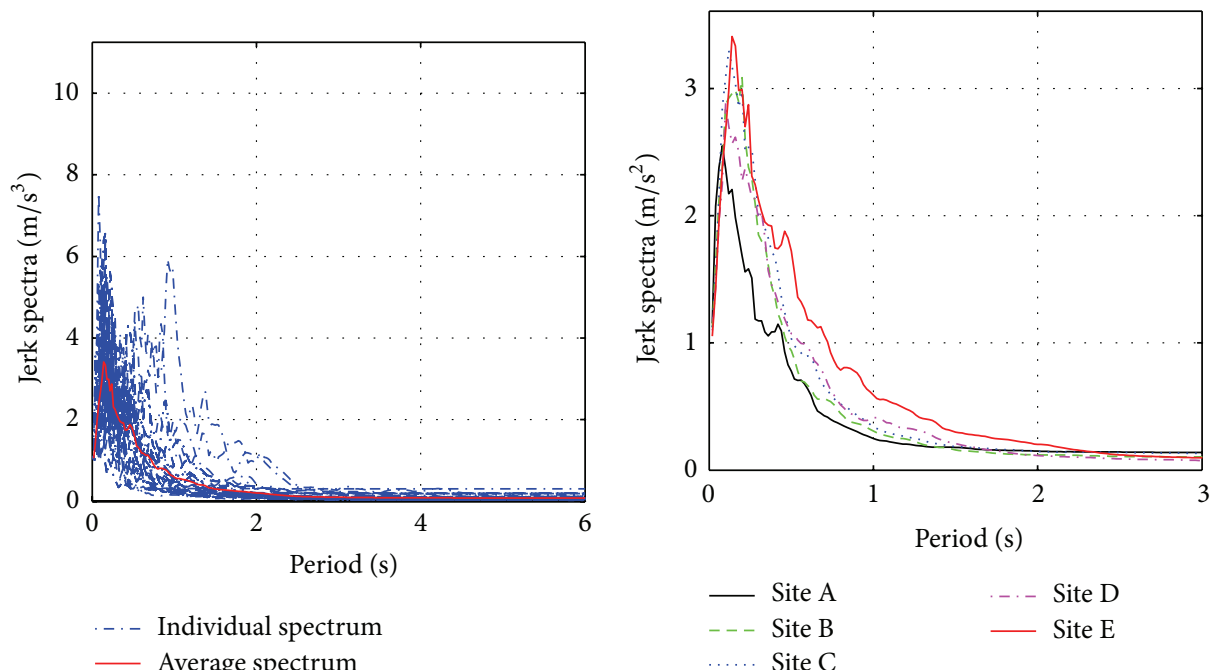

(f)

FigURE 5: Normal jerk response spectra for different sites. 


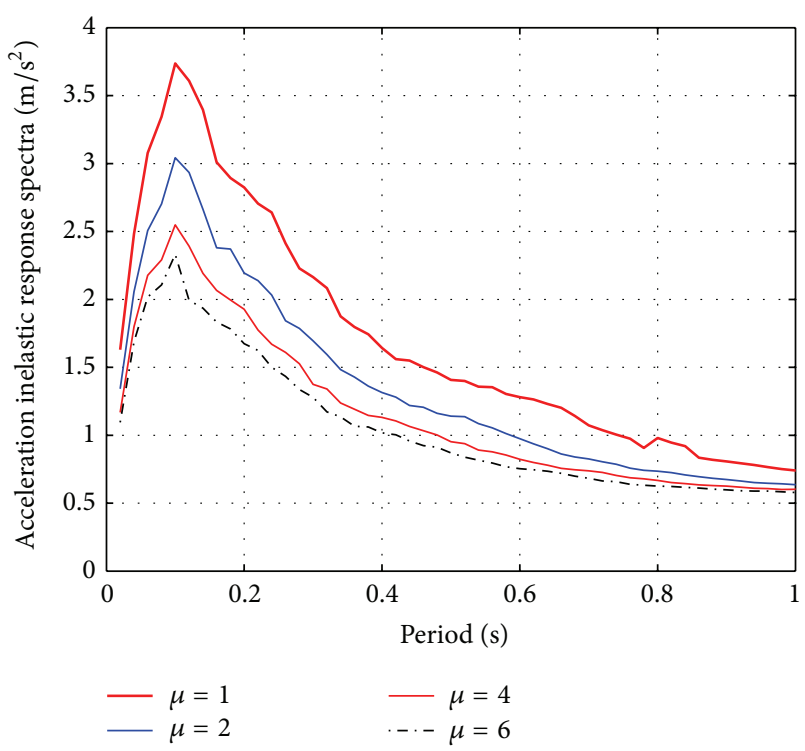

Figure 6: Acceleration inelastic response spectra for site A.

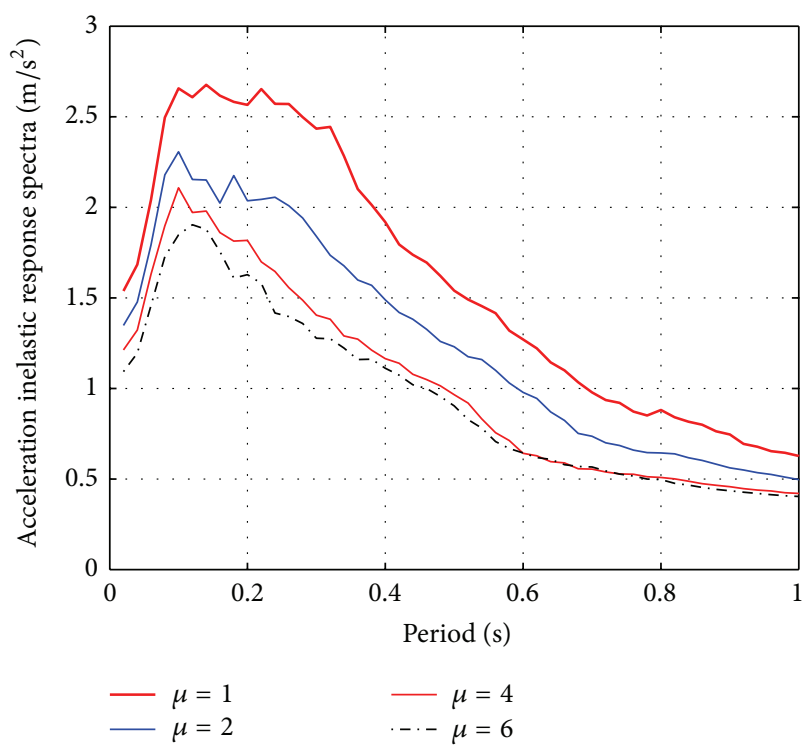

Figure 7: Acceleration inelastic response spectra for site C.

With the development of numerical technology, now it is possible to determine the strength reduction factor $R$ by theoretical analysis. The corresponding results suggest that earthquake magnitude and epicenter distance have no great influence on $R$, but ductility $\mu$, period of structures $T$, shape of hysteresis loop, and site profile exactly influence $R$. Different $R-\mu-T$ were proposed by many researchers [16-21]. Although the fitting formula for the strength reduction factor spectra with equal ductility is over ten forms, the physical meaning of the formula proposed by Vidic et al. is concise and could be easily accepted [20]:

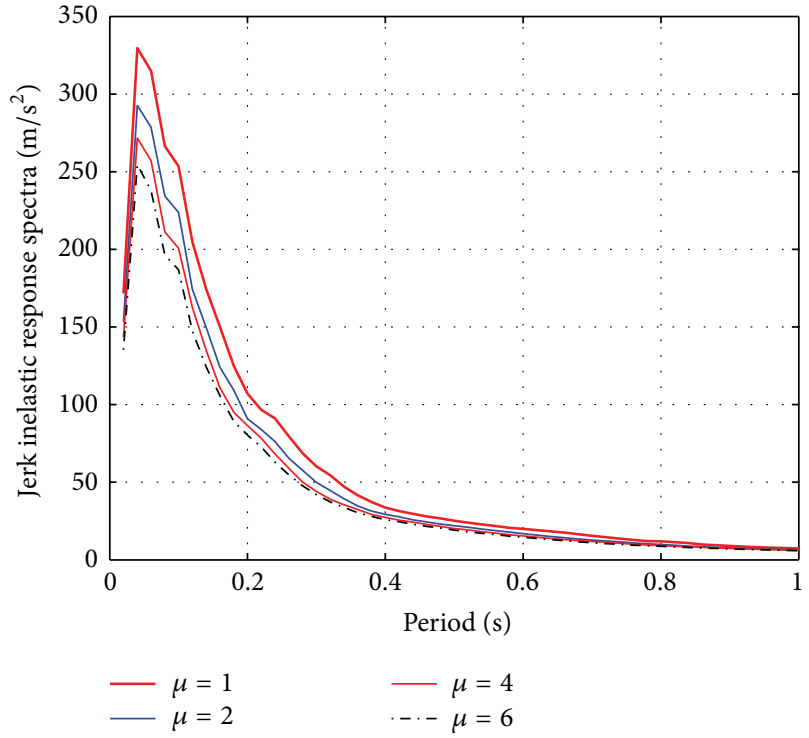

FIGURE 8: Jerk inelastic response spectra for site A.

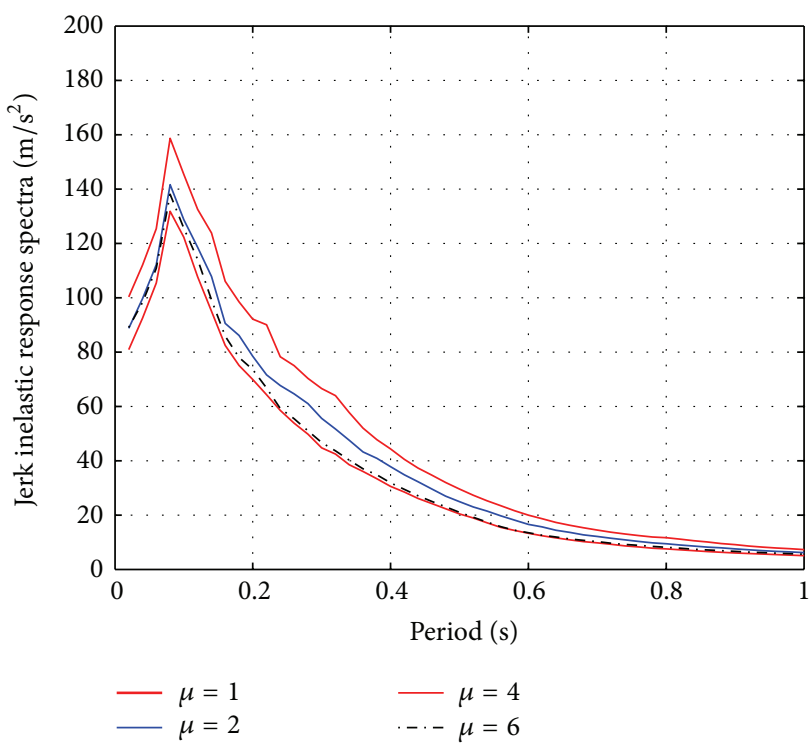

Figure 9: Jerk inelastic response spectra for site C.

$$
\begin{array}{r}
R=c_{1}(\mu-1)^{c_{R}} \frac{T}{T_{0}}+1, \quad T \leq T_{0} \\
R=c_{1}(\mu-1)^{c_{R}}+1, \quad T \geq T_{0} \\
T_{0}=c_{2} \mu^{c_{R}} T_{1},
\end{array}
$$

where $T_{1}$ is the period about peak ground motion and amplification factors and $c_{1}, c_{2}, c_{R}$, and $c_{T}$ depend on the hysteretic behavior and damping. 


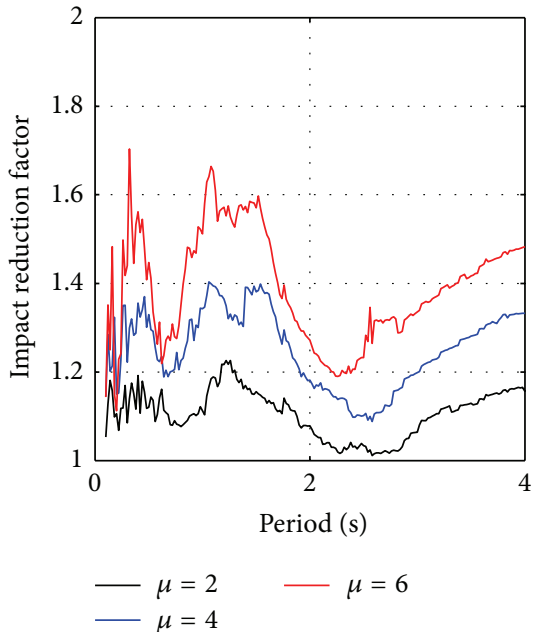

(a)

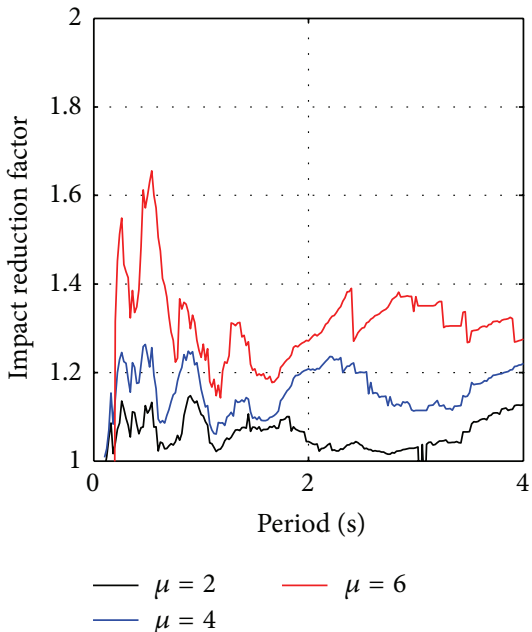

(b)

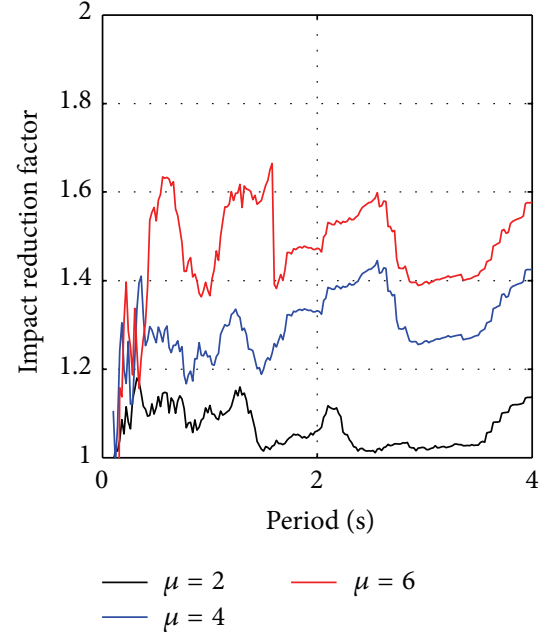

(c)

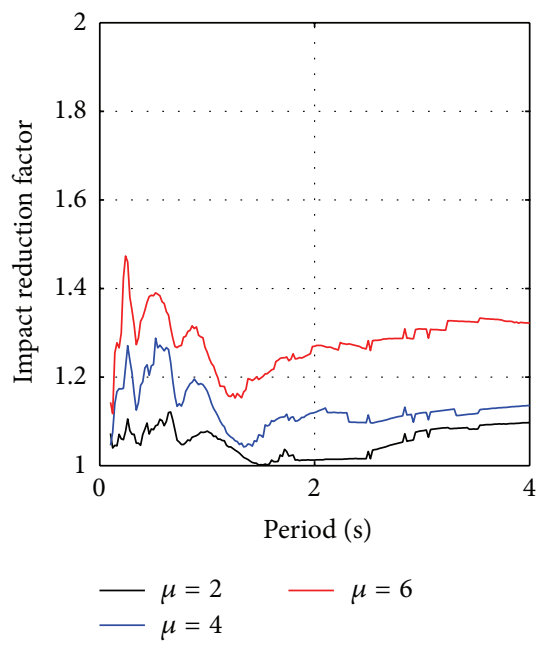

(d)

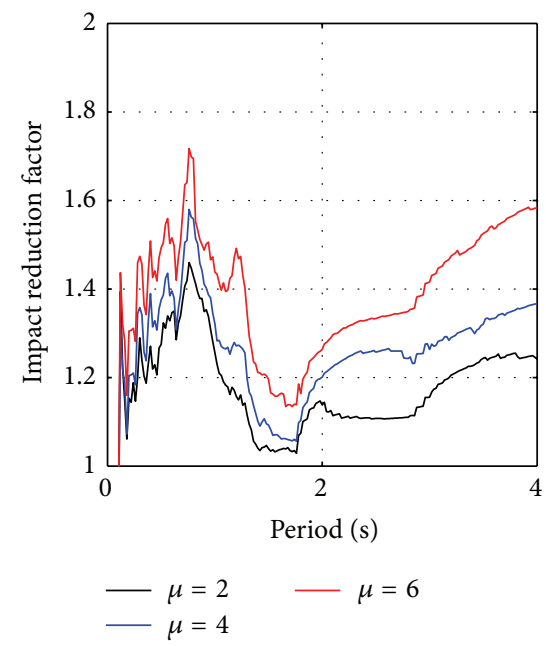

(e)

FIGURE 10: Impact reduction factor for different soil types.

To study the jerk effect on the dynamic performance of the elastic-plastic structure, the concept of impact reduction factor is presented in this paper as follows:

$$
R_{J}=\frac{J_{x e}}{J_{x p}}
$$

where $J_{x e}$ is the maximum jerk of SDOF elastic system subjected to a given ground motion and $J_{x p}$ is the maximum jerk response of the structure with the determined displacement ductility.

According to the site type and the specified ductility factor, the impact reduction factor spectra are obtained by computation and statistics, and the corresponding ground motions are listed in Table 2. The impact reduction factor for different sites and ductility are shown in Figure 10. The results show that the impact reduction factor is nonstationary, and the coefficient variation is over 0.8 in some cases. Different from the strength reduction factor, the impact reduction factor is nearly not relevant to the period but has limited values for different ductilities, especially for structure with short period, because of the high nonstationary behavior of jerk whether in low frequency band or high frequency band. The empirical formula of the upper limit of the impact reduction factor can be written as

$$
R_{J}(T, \mu, \zeta) \leq \frac{\zeta_{n}}{\zeta}(1+0.1 \mu)
$$

where $\zeta_{n}$ is the normal damping ratio 0.05 . The trends and range of impact reduction factor suggest that the attenuation of jerk is nearly not relevant to the period.

As expressed in (17), the strength reduction factor in the predominant period is a linear function on the natural period. However, the impact reduction factor is irrelevant to the natural period. It is liable to understand the difference considering jerk is the derivative of acceleration, but the essence relationship between the impact reduction factor and the strength reduction factor needs to be further studied. 


\section{Conclusions and Recommendations}

This study investigated the characteristics of jerk which means the time rate of change of acceleration, and there are few researches in this field. In fact, jerk mainly represents the nonstationary component in high frequency of the earthquake wave. The step-by-step integration method based on the assumption of linear acceleration does not satisfy the theoretical basis and precision of jerk calculation; therefore, the fourth-order Runge-Kutta method is used to compute the jerk response according to the dynamic equation. Furthermore, the state-space equation on jerk is presented.

Jerk spectrum indicates the impact effect for the structures with different periods. The amplification effect on jerk is obvious when the system period is close to the predominant period of the site. Compared to the rock site, the predominant period range in the soft soil site is larger, and the jerk response is more obvious for long period structure on soft site.

Based on inelastic analysis, the response of SDOF systems and the jerk inelastic response spectra are established, and the influence factors such as site type, ductility, and the corresponding response parameter such as impact reduction factor are discussed.

The results show that the jerk spectrum has similar rules as acceleration spectrum in general, and the amplitude is relative to the predominant period, especially for structures with short or medium period. If the ductility is improved, the effective jerk will reduce obviously, and the impact reduction factor will be enhanced. Different from the strength reduction factor, the impact reduction factor is nearly not relevant to the period, so that the structural jerk and corresponding parameter are advised to be considered for all the structures if possible in the building design.

Jerk spectrum needs intensive study as the ground motion is a complex multidimensional fluctuation of the near surface, and the influencing factors such as pulse effects on the near field and attenuation phenomenon on far field are suggested to be considered in the future. In addition, the statistical regularity on the impact reduction factor and the complex relationship between the impact reduction factor and the strength reduction factor will contribute to the understanding of ground motion. The application of jerk spectrum in conjunction with the normal building design is also needed.

\section{Conflict of Interests}

The authors declare that there is no conflict of interests regarding the publication of this paper.

\section{Acknowledgments}

This work is partially supported by the Natural Science Foundation of China under Grants nos. 51478024 and 51108009 and Foundation of Beijing Key Lab of Earthquake Engineering and Structural Retrofit under Grant no. USDE201403.

\section{References}

[1] K. Goda and H. P. Hong, "Spatial correlation of peak ground motions and response spectra," Bulletin of the Seismological Society of America, vol. 98, no. 1, pp. 354-365, 2008.

[2] M. Wang and T. Takada, "Macrospatial correlation model of seismic ground motions," Earthquake Spectra, vol. 21, no. 4, pp. 1137-1156, 2005

[3] L. Dong and X. Li, "A microseismic/acoustic emission source location method using arrival times of PS waves for unknown velocity system," International Journal of Distributed Sensor Networks, vol. 2013, Article ID 307489, 8 pages, 2013.

[4] J. N. Brune, "Tectonic stress and the spectra of seismic shear waves from earthquakes," Journal of Geophysical Research, vol. 75, no. 26, pp. 4997-5009, 1970.

[5] Y.-M. Wu, N.-C. Hsiao, and T.-L. Teng, "Relationships between strong ground motion peak values and seismic loss during 1999 Chi-Chi, Taiwan Earthquake," Natural Hazards, vol. 32, no. 3, pp. 357-373, 2004.

[6] X. Li and L. Dong, "An efficient closed-form solution for acoustic emission source location in three-dimensional structures," AIP Advances, vol. 4, no. 2, Article ID 027110, 2014.

[7] S. H. Schot, "Jerk: the time rate of change of acceleration," The American Journal of Physics, vol. 11, no. 46, p. 1090, 1978.

[8] A. Toshiyuki, S. Yutaka, and I. Tomokazu, "Cycle slip detection in kinematic GPS with a jerk model for land vehicles," International Journal of Innovative Computing Information and Control, vol. 21, no. 4, pp. 153-166, 2009.

[9] C. Liu, D. C. Gazis, and T. W. Kennedy, "Human judgment and analytical derivation of ride quality," Transportation Science, vol. 33, no. 3, pp. 290-297, 1999.

[10] D. Hrovat and M. Hubbard, "A comparison between jerk optimal and acceleration optimal vibration isolation," Journal of Sound and Vibration, vol. 112, no. 2, pp. 201-210, 1987.

[11] M. Tong, G.-Q. Wang, and G. C. Lee, "Time derivative of earthquake acceleration," Earthquake Engineering and Engineering Vibration, vol. 4, no. 1, pp. 1-16, 2005.

[12] X.-S. Yang, X.-Z. Qi, G. C. Lee, M. Tong, and J.-M. Cao, "Sensor for measuring the derivative of acceleration component," Journal of Vibration and Shock, vol. 27, no. 12, pp. 143-147, 2008.

[13] J. G. Chase, L. R. Barroso, and S. Hunt, "Quadratic jerk regulation and the seismic control of civil structures," Earthquake Engineering and Structural Dynamics, vol. 32, no. 13, pp. 20472062, 2003.

[14] R. W. Clough and J. Penzien, Dynamics of Structures, McGrawHill, New York, NY, USA, 1993.

[15] A. K. Chopra, Dynamics of Structures: Theory and Applications to Earthquake Engineering, Prentice-Hall, New Delhi, India, 2007.

[16] L. H. Lee, S. W. Han, and Y. H. Oh, "Determination of ductility factor considering different hysteretic models," Earthquake Engineering and Structural Dynamics, vol. 28, no. 9, pp. 957-977, 1999.

[17] N. M. Newmark and W. J. Hall, Procedures and Criteria for Earthquake Resistant Design, Building Research Series no. 46, National Bureau of Standards, U.S. Department of Commerce, Washington, DC, USA, 1973.

[18] H. Krawinkler and A. A. Nassar, "Seismic design based on ductility and cumulative damage demand and capacities," in Nonlinear Seismic Analysis and Design of Reinforced Concrete Buildings, pp. 23-40, Elsevier Applied Science, New York, NY, USA, 1992. 
[19] E. Miranda and V. Bertero, "Evaluation of strength reduction factors for earthquake-resistant design," Earthquake Spectra, vol. 10, no. 3, pp. 357-379, 1994.

[20] T. Vidic, P. Fajfar, and M. Fischinger, "Consistent inelastic design spectra: strength and displacement," Earthquake Engineering \& Structural Dynamics, vol. 23, no. 5, pp. 507-521, 1994.

[21] B. Borzi and A. S. Elnashai, "Refined force reduction factors for seismic design," Engineering Structures, vol. 22, no. 10, pp. 12441260, 2000. 

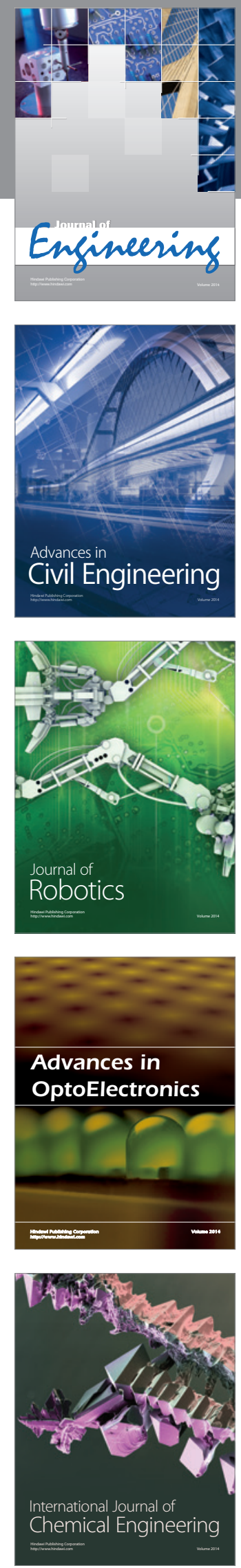

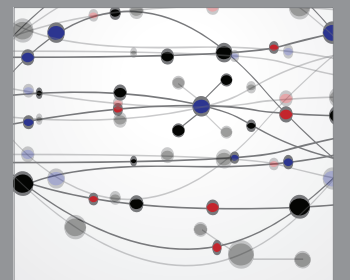

The Scientific World Journal
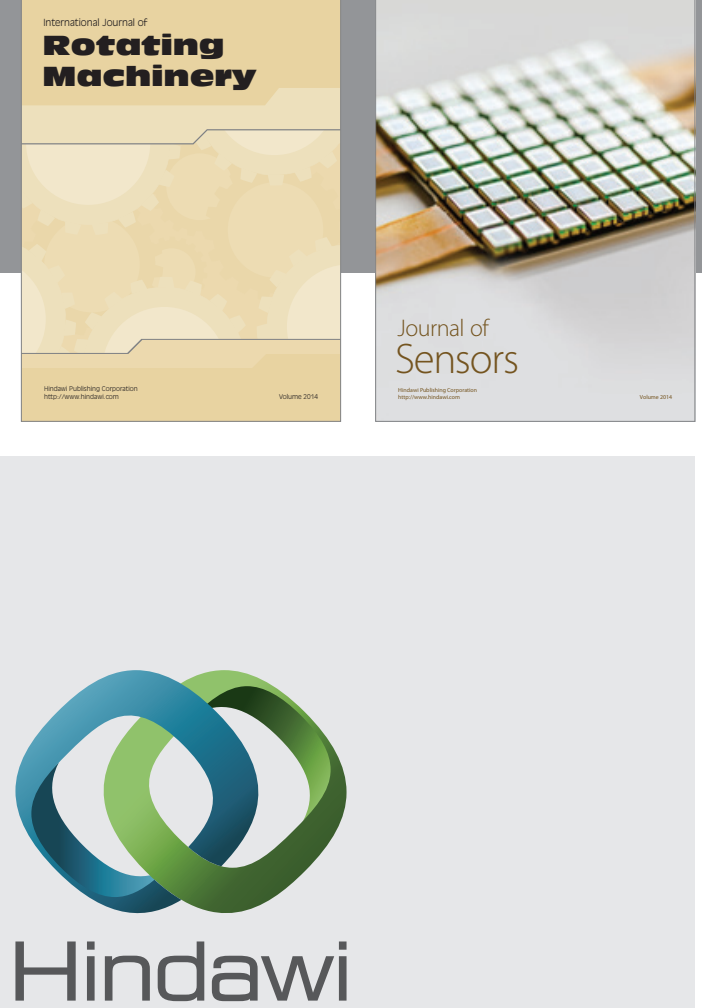

Submit your manuscripts at http://www.hindawi.com
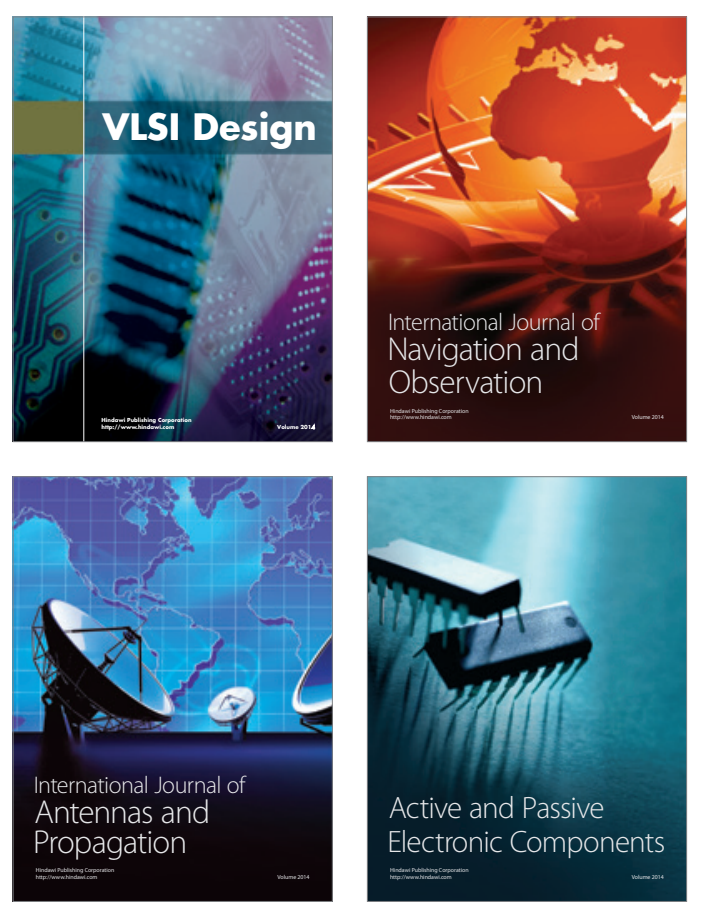
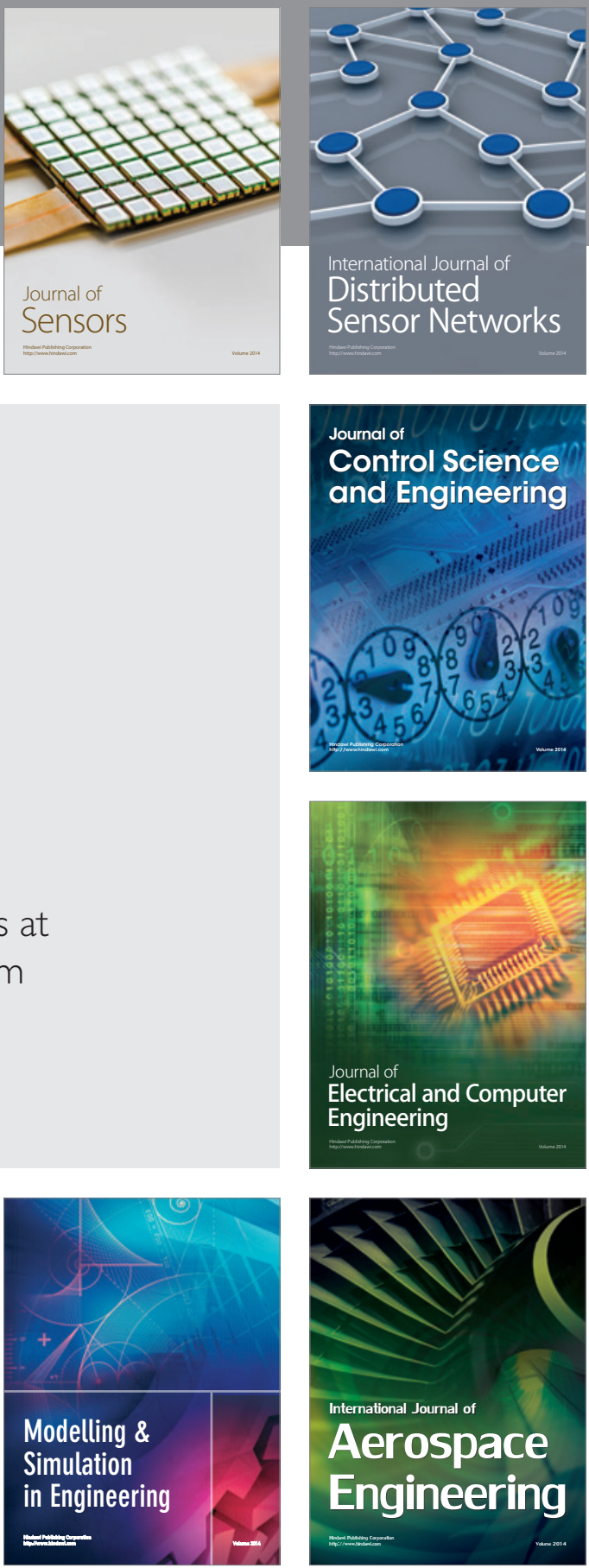

Journal of

Control Science

and Engineering
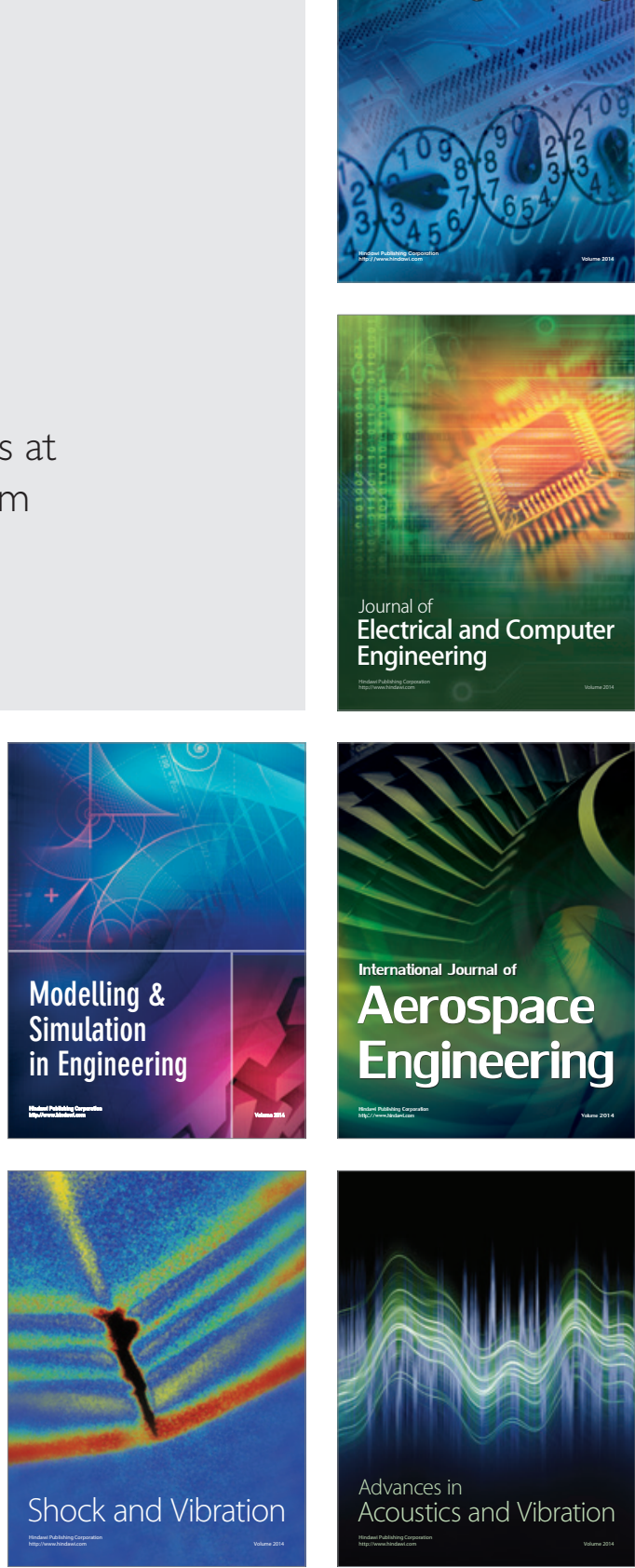